\title{
Using Breast MRI to Evaluate Complications of Autologous Fat Grafting
}

Li-Kuo Shen ${ }^{1}$, Shoei-Loong Lin ${ }^{2}$, Cheuk-Sing Choy ${ }^{3}$, Wing P Chan ${ }^{4}$, Mimmo Gasbarri ${ }^{5}$ and Ting-Kai Leung,6*

${ }^{1}$ Department of Radiology, Shuang Ho Hospital, Taipei Medical University, New Taipei City 235, Taiwan

${ }^{2}$ Department of Surgery, Taipei Hospital, Ministry of health and Welfare, Taiwan., R.O.C and Department of Surgery, School of Medicine, College of Medicine, Taipei

Medical University, Taiwan

${ }^{3}$ Department of Emergency and Intensive Care, Taipei Hospital, Department of Health, Taiwan

${ }^{4}$ Department of Radiology, School of Medicine, College of Medicine, Taipei Medical University and Department of Radiology, Wan Fang Hospital, Taipei Medical

University, Taiwan

${ }^{5}$ Dept. of Natural Health Studies / London College of Training \& Management, London, UK

${ }^{6}$ Diagnostic Radiology Department, Taipei Hospital, Ministry of Health and Welfare, Taiwan

\begin{abstract}
Introduction: During the past few years in Taiwan, there has been a rapid growth of autologous fat grafting procedures performed for cosmetic reasons. We retrospectively demonstrate Complications of Autologous Fat Grafting in the breast, based on clinical presentations and breast MRI imaging. We also discuss the possible method of early detection of complications.

Material and method: Twenty-one ethnic Chinese (Taiwanese) women were transferred for delicate breast MRI study in the past year. These patients had suffered different signs and symptoms following the procedure. Clinical and image information were collected from the hospital database.

Results: Breast MRI successfully detected all viable fat tissues and complicated lesions of the breasts. The image findings corresponded to the clinical presentation and were used in therapeutic decision making. Fat necrosis with granuloma formations caused by graft rejection was the main complications. The most severe complication was an abscess formation and impending sepsis. Management procedures included operation or drainage; received oral antibiotics; and received clinical observation.

Discussion and Conclusion: MRI is capable of detecting the surviving fat graft tissues, and to distinguish degree of malignancy from benign lesions. In complicated cases, the highest incidences showed granuloma formations and fat necrosis. However, laboratory data such as CRP, IgE and complement (C3 \&C4) levels only reflected some of the infectious cases and could not be used as monitoring parameters. Breast MRI is an ideal tool for early detection of autologous fat complications without causing indistinguishable conclusions from malignancy. Breast MRI should be performed as early as possible for this complication, so that help for early treatment can be planned.
\end{abstract}

Keywords: Breast MRI; Autologous fat graft; Survive; Abscess formation; Fat necrosis; Rejection; Complication

\section{Introduction}

Autologous fat grafting is a technique that involves using the patient's own adipose tissue to be applied on a subcutaneous area of the body to increase total fat volume [1-3]. Breast augmentation using autologous fat grafting is not associated with implant related problems such as implant leakage, breast deflation, visible or palpable implants, or the development of breast capsular contracture. Regarding successful cases of autologous fat grafting, under the condition of suspected tumor growth, a usual biopsy procedure can be performed without risk of a stabbing rupture of the implanted materials. However, autologous fat grafting in the breast is not a simple procedure and should be performed by highly trained and skilled surgeons. The recipient of autologous fat grafting is at risk of intraoperative pneumothorax, calcification, multiple cyst formation [4], focal breast indurations, pain, infection, and abscesses [5], abnormal breast discharge, and reactive lymphadenopathy. In contrast to the aforementioned successful cases, these patients require life-long follow up for breast cancer screening because of the difficulty of cancer detection. These patients should also undergo long-term imaging analyses [6,7]. Autologous fat grafts are also believed to have the disadvantage of the unpredictability graft tissue survival because of fat necrosis and re-absorption [8]. The incidence of calcifications (mostly due to fat necrosis) after all types of breast operations varies, but has been reported in as many as 50 percent of patients within 2 years [9].

It was also reported that breast asymmetrical densities were present in approximately half of patients throughout the follow-up period of post-mammoplasty. In additions, fat necrosis occurred in approximately one tenth of the patients [9]. Many plastic surgeons have rejected fat grafting in the breast because of the speculation that transplanted fat might undergo necrosis or die off gradually, forming lumps or calcifications. Fat grafting raises the concern of interfering with breast cancer detection. In fact, injecting small volumes of fat produces microcalcifications, which can be indistinguishable from carcinomas in mammograms; whereas injecting larger volumes might result in the liponecrotic pseudocyst formation that can interfere with physical breast examination and cause a growing and painful mass $[10,11]$. Regarding breast image screening and diagnosis for such patients, mammography is favored by radiologists to differentiate cancer microcalcifications from benign calcifications of the breast. However, most cosmetic mammoplasty patients are among the young age group that should receive non-ionized radiation screening of breast tissues. Therefore, the first line screening for this age group is usually sonography, but the sensitivity and specificity of sonography to differentiate calcification and microcalcifications is not reliable [12]. Breast MRI should be considered a first line screening tool or

${ }^{*}$ Corresponding author: Ting-Kai Leung, Department of Emergency and Intensive Care, Taipei Hospital, Department of Health, Taiwan, Tel: 886982802149; E-mail: hk8648@tmu.edu.tw

Received February 22, 2014; Accepted June 26, 2014; Published June 28, 2014

Citation: Shen LK, Lin SL, Choy CS, Chan WP, Gasbarri M, et al. (2014) Using Breast MRI to Evaluate Complications of Autologous Fat Grafting. Surgery Curr Res 4: 197. doi:10.4172/2161-1076.1000197

Copyright: $\odot 2014$ Shen LK, et al. This is an open-access article distributed under the terms of the Creative Commons Attribution License, which permits unrestricted use, distribution, and reproduction in any medium, provided the original author and source are credited. 
at least used when clinical suspicion or radiographic abnormality is indeterminate.

Breast MRI has also been reported to be more capable than mammography of early detection of fat necrosis and clinically nondetectable masses and nodules, although MRI is not used to detect calcifications or microcalcifications [13].

During the past 2 years in Taiwan, there has been a rapid growth of autologous fat grafting procedures performed for cosmetic reasons. In this study, we demonstrate cases of autologous fat grafting in the breast, including complications, based on clinical presentations and breast MRI imaging. We also discuss the possible method of early detection of the Complications of Autologous Fat Grafting of the breast.

\section{Material and Methods}

\section{Cases collections}

From March 2011 to February 2012, twenty-one ethnic Chinese (Taiwanese) women were transferred to the Breast Health Center (Taipei Medical University Hospital) for delicate breast MRI study. These patients exhibited different symptoms and signs after the procedure. Clinical and image information were collected between March 2011 and February 2012 from the hospital database. The patients were between 25 and 62 years old, and none had undergone treatment in the period between mammoplasty and breast MRI study. Furthermore, information collected and recorded included clinical expression, laboratory data such as Immunoglobulin E (IgE), Antinuclear Antibodies (ANA), complement (C3\&C4), C-Reactive Protein (CRP), antinuclear antibodies (ANA), monocyte and bacteria culture, as well as the possible pathological diagnosis and method of treatment.

\section{Image processing using delicate breast MRI}

Pre-enhanced and post-enhanced subtracted images were obtained, and an enhanced curve analysis was performed. All imaging studies were performed on a $1.5 \mathrm{~T}$ dedicated spiral breast MRI system (Aurora Systems, USA) [14-17]. The breasts were fitted and positioned using a breast transmission-receiving (TR) coil. The off-resonance spiral image mode was used. A gradient echo with $10 \mathrm{~ms}$ of TR and T2-weighted spin echo with $2.5 \mathrm{~ms}$ of TR were acquired. The echo time was $5 \mathrm{~ms}$ for RODEO and $120 \mathrm{~ms}$ for the T2 sequences. The volumetric matrix size was $360 \times 360 \times 128 \mathrm{~mm}$. The slice thickness was $1.1 \mathrm{~mm}$. The field of view of each station was $20-36 \mathrm{~cm}$. Sequences were performed before and after the infusion of $0.2 \mathrm{mmol} / \mathrm{kg}$ adolinium-diethylenetriamine pentaacetic acid (Magnevist; Bayer-Schering Pharma AG, Berlin, Germany), administered as a bolus dose with a power injector, followed by a $20-\mathrm{mL}$ saline flush. Subtraction images were also performed [14-17].

\section{Results}

According to our data on these 21 patients (Table 1), the complications may have developed 12 days to 24 months later after

\begin{tabular}{|c|c|c|c|c|c|c|c|c|}
\hline Case No. & Age & $\begin{array}{l}\text { Period of } \\
\text { autologous } \\
\text { fat graft }\end{array}$ & $\begin{array}{l}\text { Symptoms } \\
\text { and signs }\end{array}$ & Image findings on MRI & $\begin{array}{l}\text { Visibility } \\
\text { of grafted } \\
\text { fat }\end{array}$ & Laboratory data & $\begin{array}{l}\text { Clinical or } \\
\text { pathological } \\
\text { diagnosis }\end{array}$ & Treatment \\
\hline \multirow{3}{*}{$\begin{array}{l}\text { Case } 1 \\
\text { (Figure 1) }\end{array}$} & \multirow{3}{*}{35} & \multirow{3}{*}{12 days } & \multirow{3}{*}{$\begin{array}{l}\text { Pain and } \\
\text { fever }\end{array}$} & \multirow{3}{*}{$\begin{array}{l}\text { (1)Right breast enhanced cavities } \\
\text { (2)Ipsilateral lymphadenopathy }(>2 \mathrm{~cm})\end{array}$} & \multirow{3}{*}{ Yes } & (1) Anemia & (1) Abscess & \multirow{3}{*}{$\begin{array}{l}\text { Operation } \\
\text { and } \\
\text { drainage }\end{array}$} \\
\hline & & & & & & $\begin{array}{l}\text { (2) Significant CRP } \\
\text { elevation }\end{array}$ & $\begin{array}{l}\text { (2) Impending } \\
\text { sepsis }\end{array}$ & \\
\hline & & & & & & $\begin{array}{l}\text { (3) Bacterial } \\
\text { culture:Candida albicans } \\
\text { isolated }\end{array}$ & & \\
\hline \multirow{4}{*}{$\begin{array}{l}\text { Case } 2 \\
\text { (Figure 2) }\end{array}$} & \multirow{4}{*}{30} & \multirow{4}{*}{4 months } & \multirow{4}{*}{$\begin{array}{l}\text { Right breast } \\
\text { tenderness } \\
\text { with lump }\end{array}$} & \multirow{2}{*}{$\begin{array}{l}\text { (1)Multiple granulomas and abscess } \\
\text { formation at deep superior } \\
\text { and subareolar region of right breast. The } \\
\text { largest one is over } 3.2 \mathrm{~cm} \text {. }\end{array}$} & \multirow{4}{*}{ Yes } & (1) $\lg E$ elevation & \multirow{4}{*}{$\begin{array}{l}\text { Mastitis and } \\
\text { granulomatous } \\
\text { formation }\end{array}$} & \multirow{4}{*}{$\begin{array}{l}\text { Operation } \\
\text { and } \\
\text { drainage }\end{array}$} \\
\hline & & & & & & (2) Monocyte increase & & \\
\hline & & & & \multirow{2}{*}{$\begin{array}{l}\text { (2)Mild inflammation of pectoral } \\
\text { major muscle. }\end{array}$} & & (3) CRP normal & & \\
\hline & & & & & & $\begin{array}{l}\text { (4) Bacterial Culture: No } \\
\text { growth }\end{array}$ & & \\
\hline \multirow[t]{2}{*}{$\begin{array}{l}\text { Case } 3 \\
\text { (Figure 3) }\end{array}$} & \multirow[t]{2}{*}{27} & \multirow[t]{2}{*}{3 months } & \multirow[t]{2}{*}{$\begin{array}{l}\text { Tenderness at } \\
\text { bilateral sides }\end{array}$} & $\begin{array}{l}\text { (1) Diffuse granuloma formations, pockets of } \\
\text { thick wall pockets with various sizes, within } \\
\text { glandular tissues of bilateral breasts.Suggest } \\
\text { process of fat necrosis and non-infectious } \\
\text { inflammatory process }\end{array}$ & \multirow[t]{2}{*}{ Yes } & \multirow[t]{2}{*}{ Nil } & \multirow[t]{2}{*}{$\begin{array}{l}\text { Mastitis and } \\
\text { granulomatous } \\
\text { formation }\end{array}$} & \multirow[t]{2}{*}{ Observation } \\
\hline & & & & $\begin{array}{l}\text { (2)Nonspecific enlarged LNs at bilateral } \\
\text { breast axillary regions. }\end{array}$ & & & & \\
\hline \multirow{3}{*}{$\begin{array}{l}\text { Case } 4 \\
\text { (Figure 4) }\end{array}$} & \multirow{3}{*}{51} & \multirow{3}{*}{24 months } & $\begin{array}{l}(1) \\
\text { Tenderness at } \\
\text { bilateral sides }\end{array}$ & $\begin{array}{l}\text { (1)Multiple small ill defined encapsulate fat } \\
\text { masses, most of the } \\
\text { masses exhibit wall enhancement. }\end{array}$ & \multirow{3}{*}{ Yes } & \multirow{3}{*}{ Nil } & \multirow{3}{*}{$\begin{array}{l}\text { Mastitis and } \\
\text { granulomatous } \\
\text { formation }\end{array}$} & \multirow{3}{*}{$\begin{array}{l}\text { Oral } \\
\text { Antibiotics }\end{array}$} \\
\hline & & & \multirow[t]{2}{*}{$\begin{array}{l}\text { (2) Middle } \\
\text { chest pain }\end{array}$} & $\begin{array}{l}\text { (2)Focal inflammatory lesion at anterior of } \\
\text { sternum, with } 1.8 \mathrm{~cm} \text {. }\end{array}$ & & & & \\
\hline & & & & (3) Non specific reactive axillary LNs. & & & & \\
\hline \multirow{4}{*}{$\begin{array}{l}\text { Case } 5 \\
\text { (Figure 5) }\end{array}$} & \multirow{4}{*}{25} & \multirow{4}{*}{8 months } & \multirow{4}{*}{$\begin{array}{l}\text { Palpable } \\
\text { lumps at } \\
\text { superior of } \\
\text { right breast } \\
\text { and medial of } \\
\text { left breast }\end{array}$} & $\begin{array}{l}\text { 1) Diffuse granuloma formations, pockets of } \\
\text { thick wall pockets with various }\end{array}$ & & & & \\
\hline & & & & $\begin{array}{l}\text { sizes, within glandular tissues of bilateral } \\
\text { breasts. }\end{array}$ & & & $\begin{array}{l}\text { Mastitis and } \\
\text { granulomatous }\end{array}$ & \\
\hline & & & & $\begin{array}{l}\text { Suggest process of fat necrosis and non- } \\
\text { infectious inflammatory process }\end{array}$ & Yes & NII & $\begin{array}{l}\text { granulomatous } \\
\text { formation }\end{array}$ & Observatıon \\
\hline & & & & $\begin{array}{l}\text { (2)Nonspecific enlarged LNs at bilateral } \\
\text { breast axillary region. }\end{array}$ & & & & \\
\hline
\end{tabular}


Citation: Shen LK, Lin SL, Choy CS, Chan WP, Gasbarri M, et al. (2014) Using Breast MRI to Evaluate Complications of Autologous Fat Grafting Surgery Curr Res 4: 197. doi:10.4172/2161-1076.1000197

Page 3 of 12

\begin{tabular}{|c|c|c|c|c|c|c|c|c|}
\hline \multirow{2}{*}{$\begin{array}{l}\text { Case } 6 \\
\text { (Figure 6) }\end{array}$} & \multirow[t]{2}{*}{44} & \multirow{2}{*}{1 months } & \multirow{2}{*}{$\begin{array}{l}\text { Palpable } \\
\text { lumps at } \\
\text { superior of } \\
\text { right breast }\end{array}$} & $\begin{array}{l}\text { (1)Multiple granulomas like masses at } \\
\text { right breast. Suggest ongoing process of } \\
\text { inflammation with fat necrosis, }\end{array}$ & \multirow[t]{2}{*}{ Yes } & \multirow[t]{2}{*}{ Nil } & \multirow{2}{*}{$\begin{array}{l}\text { Mastitis and } \\
\text { granulomatous } \\
\text { formation }\end{array}$} & \multirow{2}{*}{$\begin{array}{l}\text { Oral } \\
\text { Antibiotics }\end{array}$} \\
\hline & & & & $\begin{array}{l}\text { (2) Possibility of mild infection is also } \\
\text { considered. }\end{array}$ & & & & \\
\hline \multirow{4}{*}{$\begin{array}{l}\text { Case } 7 \\
\text { (Figure 7) }\end{array}$} & \multirow{4}{*}{26} & \multirow{4}{*}{12 months } & \multirow{4}{*}{$\begin{array}{l}\text { Palpable } \\
\text { lumps }\end{array}$} & $\begin{array}{l}\text { (1)Multiple granulomas like masses at } \\
\text { bilateral breasts. }\end{array}$ & \multirow{4}{*}{ Yes } & (1) $\lg \mathrm{E}$ elevation & \multirow{4}{*}{$\begin{array}{l}\text { Mastitis and } \\
\text { granulomatous } \\
\text { formation }\end{array}$} & \multirow{4}{*}{ Observation } \\
\hline & & & & \multirow{3}{*}{$\begin{array}{l}\text { (2)Obvious abnormal } \mathrm{LNs}(>1.5 \mathrm{~cm} \text {, dense) at } \\
\text { bilateral breasts axillary regions. }\end{array}$} & & $\begin{array}{l}\text { (2) Antinuclear } \\
\text { Antibodies (ANA): 1:40 } \\
\text { (elevation) }\end{array}$ & & \\
\hline & & & & & & $\begin{array}{l}\text { (3) Significant } \\
\text { (complement,C4) } \\
\text { :elevation }\end{array}$ & & \\
\hline & & & & & & (4) Normal CRP & & \\
\hline \multirow{2}{*}{$\begin{array}{l}\text { Case } 8 \\
\text { (Figure } 8 \text { ) }\end{array}$} & \multirow{2}{*}{62} & \multirow{2}{*}{12 months } & \multirow{2}{*}{$\begin{array}{l}\text { Palpable } \\
\text { lumps at right } \\
\text { breast }\end{array}$} & $\begin{array}{l}\text { (1) Right breast mass; and other smaller } \\
\text { nodular lesions in bilateral breasts }\end{array}$ & \multirow{2}{*}{ Yes } & \multirow{2}{*}{ Nil } & \multirow{2}{*}{$\begin{array}{l}\text { Mastitis and } \\
\text { granulomatous } \\
\text { formation }\end{array}$} & \multirow{2}{*}{ Operation } \\
\hline & & & & $\begin{array}{l}\text { (2) Probably chronic inflammation due to fat } \\
\text { grafting induced granuloma formations }\end{array}$ & & & & \\
\hline \multirow{4}{*}{$\begin{array}{l}\text { Case } 9 \\
\text { (Figure 9) }\end{array}$} & \multirow{4}{*}{36} & & Inferior lump & (1)granulomas and & & & & \\
\hline & & & at right; & fat necrosis. & & & Mastitis and & \\
\hline & & 6 months & $\begin{array}{l}\text { Bilateral } \\
\text { medial pain }\end{array}$ & $\begin{array}{l}\text { (2)Suspect status of inflammatory infectious } \\
\text { or noninfectious }\end{array}$ & Yes & Nil & $\begin{array}{l}\text { granulomatous } \\
\text { formation }\end{array}$ & Antibiotics \\
\hline & & & for 2 weeks & mastitis at right breast. & & & & \\
\hline & & & & (1)Fat grafted cavities at bilateral sides of & & $\begin{array}{l}\text { (1) white cell count: } \\
\text { normal }\end{array}$ & Mastitis ; & \\
\hline Case 10 & & & $\begin{array}{l}\text { Bilateral chest } \\
\text { pain after }\end{array}$ & $\begin{array}{l}\text { subglandular regions. (2)Fluld content at left } \\
\text { side fat grafted cavities. (3)Some pockets }\end{array}$ & & (2) CRP: normal & acute stage & Operation \\
\hline (Figure 10) & 35 & 6 months & movements, & with fluid at inferior of left breast. (4)Post GD & Yes & (3) $\lg \mathrm{E}$ : normal & fat necrosis & and \\
\hline & & & for 1 months & $\begin{array}{l}\text { enhanced glandular tissues at left anterior } \\
\text { and bilateral of breast. }\end{array}$ & & $\begin{array}{l}\text { (4) } \\
\text { Complements(C3\&C4): } \\
\text { normal }\end{array}$ & $\begin{array}{l}\text { With granuloma } \\
\text { formations }\end{array}$ & \\
\hline & & & & $\begin{array}{l}\text { (1)Fat grafted pockets in bilateral sides(one } \\
\text { at Rt side and several }\end{array}$ & & $\begin{array}{l}\text { (1) White cell count: } \\
\text { normal, but neutrophil } \\
\text { predominate }(>75 \%)\end{array}$ & Fat necrosis & \\
\hline $\begin{array}{l}\text { Case } 11 \\
\text { (Figure 11) }\end{array}$ & 35 & 9 months & $\begin{array}{l}\text { Bilateral } \\
\text { breast pain } \\
\text { after } 2 \text { months }\end{array}$ & at left side) of subglandular regions. & Yes & (2) CRP: elevation & $\begin{array}{l}\text { Infectious } \\
\text { mastitis }\end{array}$ & $\begin{array}{l}\text { Oral } \\
\text { antibiotics }\end{array}$ \\
\hline & & & of fat grafts & $\begin{array}{l}\text { (2)Minimal fluid content within left side fat } \\
\text { grafted pocket. }\end{array}$ & & (3) IgE: normal & & \\
\hline & & & & $\begin{array}{l}\text { 3)Enhanced area at left side subareolar } \\
\text { region }\end{array}$ & & $\begin{array}{l}\text { (4) omplements(C3\&C4): } \\
\text { normal }\end{array}$ & & \\
\hline Case 12 & & & Palpable & $\begin{array}{l}\text { (1)Post fat grafted and fat necrosis, with } \\
\text { cavities within } \\
\text { inferior of right breast. }\end{array}$ & & $\begin{array}{l}\text { (1)White cell count: } \\
\text { normal, but neutrophil } \\
\text { predominate }(>75 \%)\end{array}$ & Fat necrosis & \\
\hline (Figure 12) & 37 & 7 months & lumps without & & Yes & (2)CRP: normal & & Observation \\
\hline & & & & & & (3)IgE: normal & Non-infectious & \\
\hline & & & & (2) Enhanced area at left side & & $\begin{array}{l}\text { (4)Complements(C3\&C4): } \\
\text { normal }\end{array}$ & mastitis & \\
\hline $\begin{array}{l}\text { Case } 13 \\
\text { (Figure 13) }\end{array}$ & 54 & 18 months & $\begin{array}{l}\text { Palpable } \\
\text { lumps without } \\
\text { pain }\end{array}$ & $\begin{array}{l}\text { Post fat grafted and fat necrosis, with } \\
\text { cavities(like honeycomb) at subglandular of } \\
\text { right breast. }\end{array}$ & Yes & Nil & Fat necrosis & Observation \\
\hline & & & Palpable & & & $\begin{array}{l}\text { (1)White cell count: } \\
\text { normal }\end{array}$ & & \\
\hline $\begin{array}{l}\text { Case } 14 \\
\text { (Figure 14) }\end{array}$ & 31 & 10 months & lumps without & Enhanced area at right side and reactive & Yes & (2)CRP: normal & Non-infectious & Observation \\
\hline & & & pain, at right & lymphadenoapthy & & (3)IgE: slightly elevation & mastitis & \\
\hline & & & & & & $\begin{array}{l}\text { (4)Complements }(\mathrm{C} 3 \& \mathrm{C} 4) \text { : } \\
\text { normal }\end{array}$ & & \\
\hline & & & Palpable & & & $\begin{array}{l}\text { (1)White cell count: } \\
\text { normal }\end{array}$ & & \\
\hline $\begin{array}{l}\text { Case } 15 \\
\text { (Fiqure 15) }\end{array}$ & 39 & 13 months & lumps without & Enhanced area at right side and reactive & Yes & (2)CRP: normal & Non-infectious & Ohservation \\
\hline & & & pain, at right & lymphadenoapthy & & (3) IgE: normal & mastitis & Unservatuon \\
\hline & & & & & & $\begin{array}{l}\text { (4)Complements(C3\&C4): } \\
\text { normal }\end{array}$ & & \\
\hline & & & Palpable & & & $\begin{array}{l}\text { (1)White cell count: } \\
\text { normal }\end{array}$ & & \\
\hline Case 16 & & & lumps & Fat necrosis, with cavities within & & (2)CRP: normal & & \\
\hline (Figure 16) & 56 & 5 months & $\begin{array}{l}\text { without pain, } \\
\text { at bilateral }\end{array}$ & $\begin{array}{l}\text { bilateral breasts. Enhanced lesion at deep of } \\
\text { left breast }\end{array}$ & Yes & $\begin{array}{l}\text { (3) lgE: remarkable } \\
\text { elevation }\end{array}$ & mastitis & Observation \\
\hline & & & breasts & & & $\begin{array}{l}\text { (4)Complements(C3\&C4): } \\
\text { normal }\end{array}$ & & \\
\hline
\end{tabular}


Citation: Shen LK, Lin SL, Choy CS, Chan WP, Gasbarri M, et al. (2014) Using Breast MRI to Evaluate Complications of Autologous Fat Grafting. Surgery Curr Res 4: 197. doi:10.4172/2161-1076.1000197

Page 4 of 12

\begin{tabular}{|c|c|c|c|c|c|c|c|c|}
\hline \multirow{4}{*}{$\begin{array}{l}\text { Case } 17 \\
\text { (Figure 17) }\end{array}$} & \multirow{4}{*}{53} & \multirow{4}{*}{4 months } & \multirow{4}{*}{$\begin{array}{l}\text { Palpable } \\
\text { lumps } \\
\text { without pain, } \\
\text { at bilateral } \\
\text { breasts }\end{array}$} & \multirow{4}{*}{$\begin{array}{l}\text { There are multiple fat grafted cavities at bil } \\
\text { sides of subglandular } \\
\text { Regions, with rim } \\
\text { enhancements and fluid like signal intensity. }\end{array}$} & \multirow{4}{*}{ Yes } & $\begin{array}{l}\text { (1)White cell count: } \\
\text { normal }\end{array}$ & \multirow{4}{*}{$\begin{array}{l}\text { Non-infectious } \\
\text { mastitis }\end{array}$} & \multirow{4}{*}{ Observation } \\
\hline & & & & & & (2)CRP: normal & & \\
\hline & & & & & & $\begin{array}{l}\text { (3) IgE: remarkable } \\
\text { elevation }\end{array}$ & & \\
\hline & & & & & & $\begin{array}{l}\text { (4)Complements(C3\&C4): } \\
\text { normal }\end{array}$ & & \\
\hline \multirow{4}{*}{$\begin{array}{l}\text { Case } 18 \\
\text { (Figure 18) }\end{array}$} & \multirow{4}{*}{24} & \multirow{4}{*}{11 months } & \multirow{4}{*}{$\begin{array}{l}\text { Palpable lump } \\
\text { at peri-areolar } \\
\text { of Lt breast }\end{array}$} & \multirow{4}{*}{$\begin{array}{l}\text { Focal enhanced non-mass lesion with } \\
\text { irregular border, at subcutaneous skin at } \\
\text { anterior lateral inferior of Lt breast. } \\
\text { No extensive fat necrosis. }\end{array}$} & \multirow{4}{*}{ Yes } & $\begin{array}{l}\text { (1)White cell count: } \\
\text { normal }\end{array}$ & \multirow{4}{*}{$\begin{array}{l}\text { Non-infectious } \\
\text { mastitis }\end{array}$} & \multirow{4}{*}{ Observation } \\
\hline & & & & & & (2)CRP: normal & & \\
\hline & & & & & & (3)lgE: normal & & \\
\hline & & & & & & $\begin{array}{l}\text { (4)Complements(C3): } \\
\text { slightly elevation }\end{array}$ & & \\
\hline $\begin{array}{l}\text { Case } 19 \\
\text { (Figure 19) }\end{array}$ & 30 & 7 months & $\begin{array}{l}\text { Palpable } \\
\text { lumps } \\
\text { without pain, } \\
\text { at bilateral } \\
\text { breasts }\end{array}$ & $\begin{array}{l}\text { Multiple fat grafted cavities at superior lateral } \\
\text { of bilateral breasts. }\end{array}$ & Yes & Nil & $\begin{array}{l}\text { Fat necrosis } \\
\text { with granuloma } \\
\text { formations }\end{array}$ & Observation \\
\hline \multirow[b]{2}{*}{$\begin{array}{l}\text { Case } 20 \\
\text { (Figure 20) }\end{array}$} & \multirow[b]{2}{*}{31} & \multirow[b]{2}{*}{3 months } & \multirow{2}{*}{$\begin{array}{l}\text { Palpable } \\
\text { lumps with } \\
\text { pain for } 2 \\
\text { months, } \\
\text { at bilateral } \\
\text { breasts }\end{array}$} & \multirow[b]{2}{*}{$\begin{array}{l}\text { Areas of enhancement with impending } \\
\text { abscess formations at superior } \\
\text { lateral of right breast }\end{array}$} & \multirow[b]{2}{*}{ Yes } & (1) Anaerobic Culture & \multirow[b]{2}{*}{$\begin{array}{l}\text { Mastitis, minimal } \\
\text { abscess }\end{array}$} & \multirow[b]{2}{*}{$\begin{array}{l}\text { Oral } \\
\text { Antibiotics }\end{array}$} \\
\hline & & & & & & (2) Aerobic Culture & & \\
\hline $\begin{array}{l}\text { Case } 21 \\
\text { (Figure 21) }\end{array}$ & 45 & 6 months & $\begin{array}{l}\text { Pain for } 2 \\
\text { months and } \\
\text { no lump }\end{array}$ & $\begin{array}{l}\text { Reactive lymphadenitis at bilateral axillary } \\
\text { regions }\end{array}$ & Yes & Nil & $\begin{array}{l}\text { Non-infectious } \\
\text { mastitis }\end{array}$ & Observation \\
\hline
\end{tabular}

Table 1: Clinical presentation, image finding and treatment of the patients.

autologous fat grafting, including infection, granuloma, and fibrotic change [18-20]. The mean of duration that represent for MRI image diagnosis was 8.1 months. All of the patients suffered from breast tenderness, palpable lumps, pain or fever. The most severe complication was immediate post-operative abscess formation and impending sepsis. All of the cases were diagnosed with fat necrosis and granuloma formations caused by fail of graft tissue survival or graft rejection. Serum test for two of the patients were exhibited CRP elevation, and serum test for IgE was also found elevated in another 3 patients. Among these 21 cases, $19 \%$ required operation or incisional drainage; $23.8 \%$ received oral antibiotics for conservative treatment; and $57.1 \%$ of the cases were suggested for observation after image diagnosis. Based on the MRI images (Figures 1-21), all of the fat grafted tissue from the 21 cases could be identified, even Case 4 , who received the procedure for over 2 years. According to the pictures of breast MRI, no case revealed a lesion indistinguishable from malignancy that required additional biopsy.

\section{Discussion}

There are two issues to discuss. Firstly, is that complications of the fat graft can be detected and survived; secondly is breast MRI is capable to distinguish malignancy from benign lesions. In early 2007 , Kaufman MR et al reported no evidence of the post autologous fat grafting fat survivability and the predictability of volume restoration. In conducting a quantitative study using large-scale clinical assessment and three-dimensional volumetric imaging to provide useful outcome data, they found that fat survival of autologous fat graft in that period is questionable [21]. By contrast, a rapid growth of new procedures
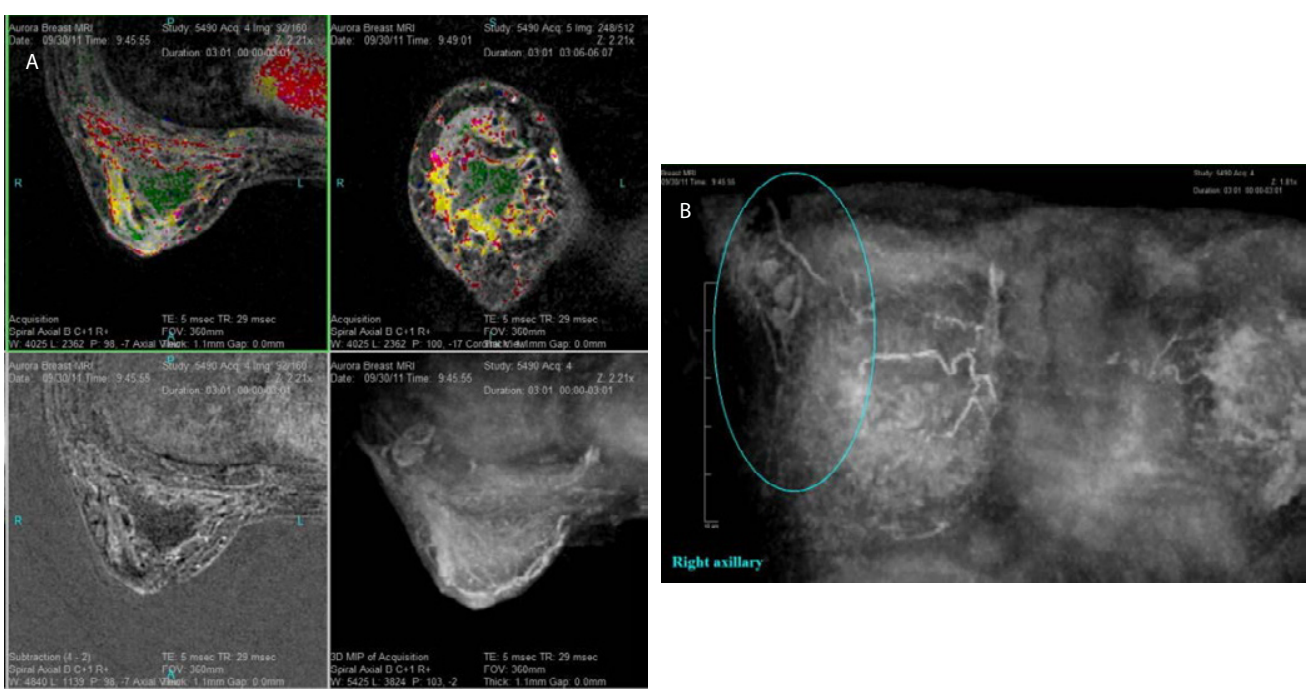

Figure $1 \mathrm{a}$ : An abscess formation at the lateral of the right breast, associate with generalized cellulitis and glandular inflammation, including the pectoral major muscle. Subtract image further rule out the possibility of malignancy.

b: Multiple reactive $>2.0 \mathrm{~cm}$ axillary lymph nodes. 
Citation: Shen LK, Lin SL, Choy CS, Chan WP, Gasbarri M, et al. (2014) Using Breast MRI to Evaluate Complications of Autologous Fat Grafting. Surgery Curr Res 4: 197. doi:10.4172/2161-1076.1000197

Page 5 of 12
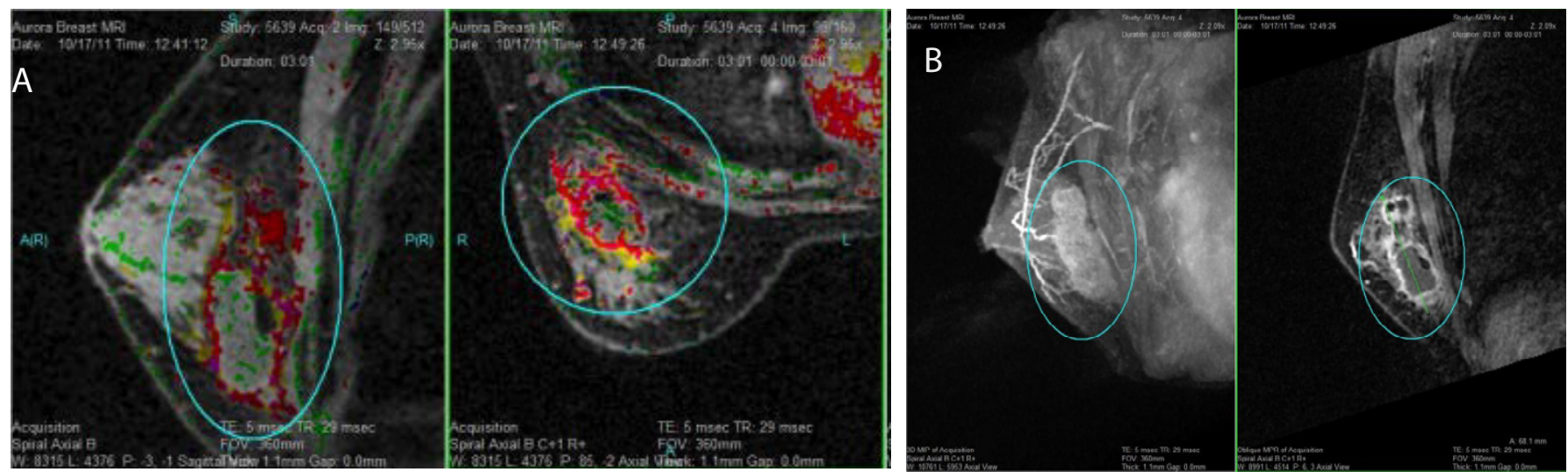

Figure 2: Multiple granulomas and abscess formation at deep superior and subareolar region of the right breast. The largest is over $3.2 \mathrm{~cm}$, with a mild inflammation of the pectoral major muscle.

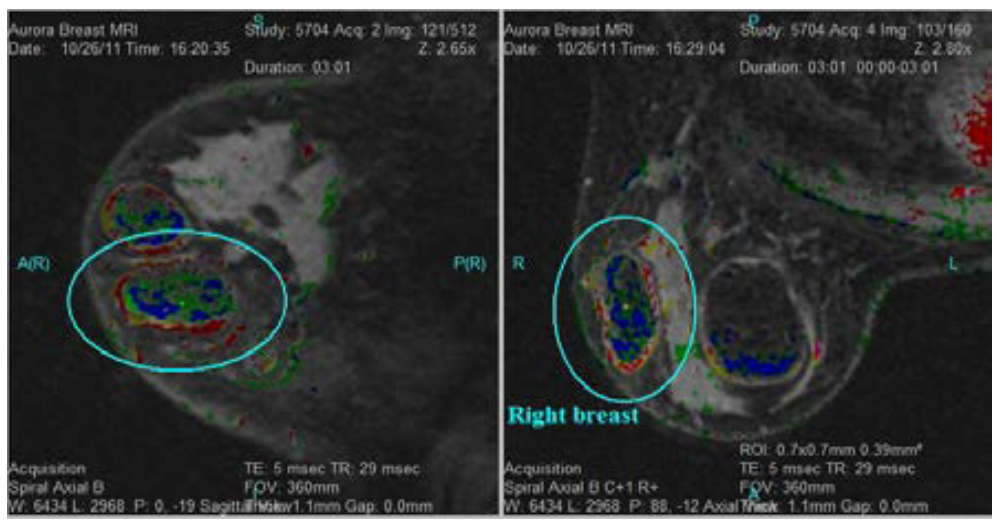

Figure 3: Thick wall pockets of various sizes within glandular tissues of the left breast. On color mapping, there are showed in different color areas represents minimal fluid, fat, protein components.
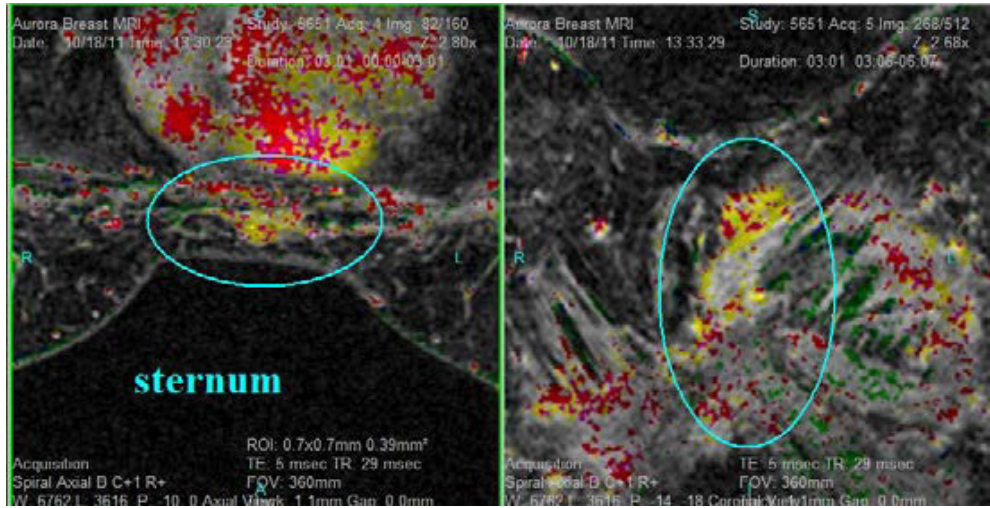

Figure 4: Focal inflammatory lesion at anterior of sternum.

used to collect larger amounts of transplantable fatty tissue by using liposuction (e.g., water-assisted liposuction); and the procedure of autologous lipo-transplantation after tissue separations. By conducting a series of procedures that focus on the superfluous water, fat purification, and centrifugation, the viable fat tissue could then be harvested [22,23]. Smith et al. using breast MRI to compare the image morphological change of fat grafted breasts before and after using this type of improved technique in operations [22]. They found that $41.1 \%$ of the studied patients exhibited a significant volume increase of grafted fat within the treated areas. The average size of increase was approximately $100-150 \mathrm{ml}$. Approximately $2.4 \%$ patients developed palpable subcutaneous nodules which finally proved to be granulomas [22]. For these cases that developed complications, the pathologic results for the excised granulomas, included fat necrosis, calcification, hyalinization, and fibroplasia [24]. Our observations support the results of these previous studies, in that the complication rate of granuloma formation (a complex of chronic inflammation with fat necrosis), is ahead of infection and mastitis. Therefore, granuloma formations due 
Citation: Shen LK, Lin SL, Choy CS, Chan WP, Gasbarri M, et al. (2014) Using Breast MRI to Evaluate Complications of Autologous Fat Grafting. Surgery Curr Res 4: 197. doi:10.4172/2161-1076.1000197

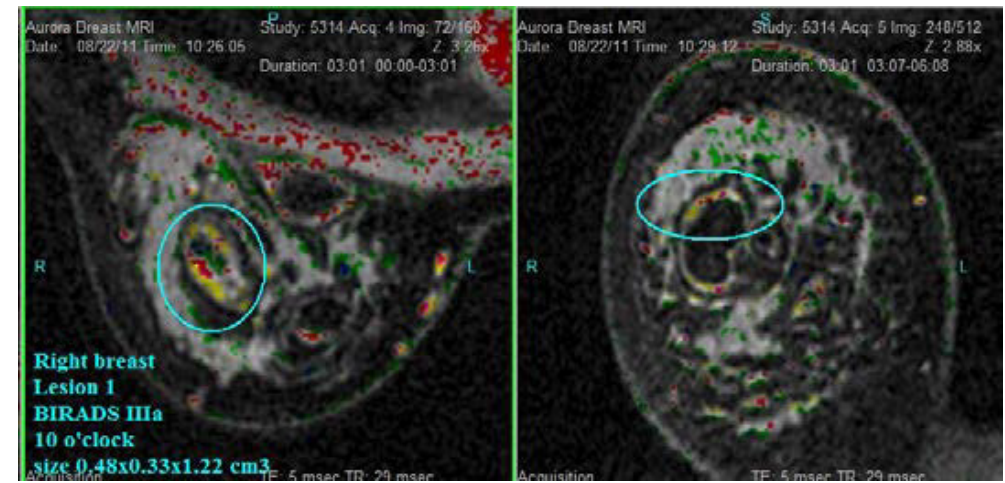

Figure 5: Multiple, large and small, ill-defined encapsulated fat masses, most of which exhibit wall enhancement.

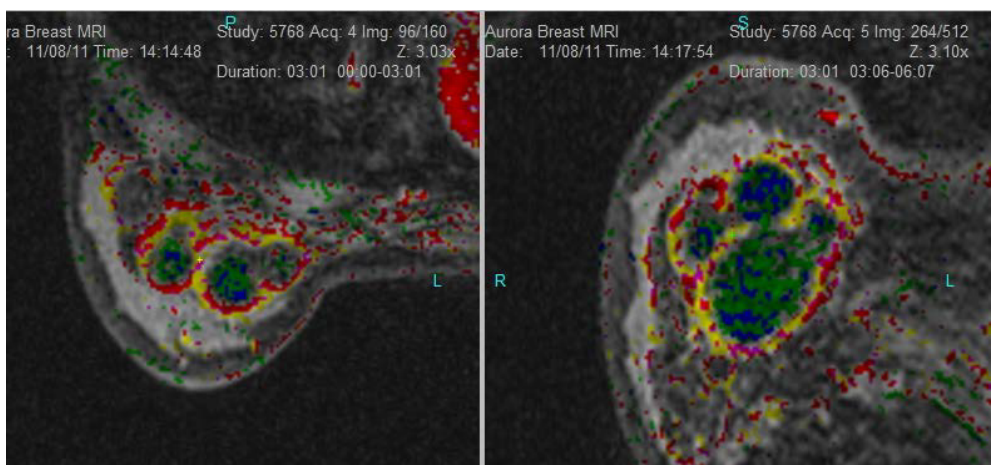

Figure 6: Multiple granuloma-like masses at the subglandular of the right breast. The largest mass $(3.0 \mathrm{~cm})$ exhibits wall enhancement with semifluid and semi-fat content.

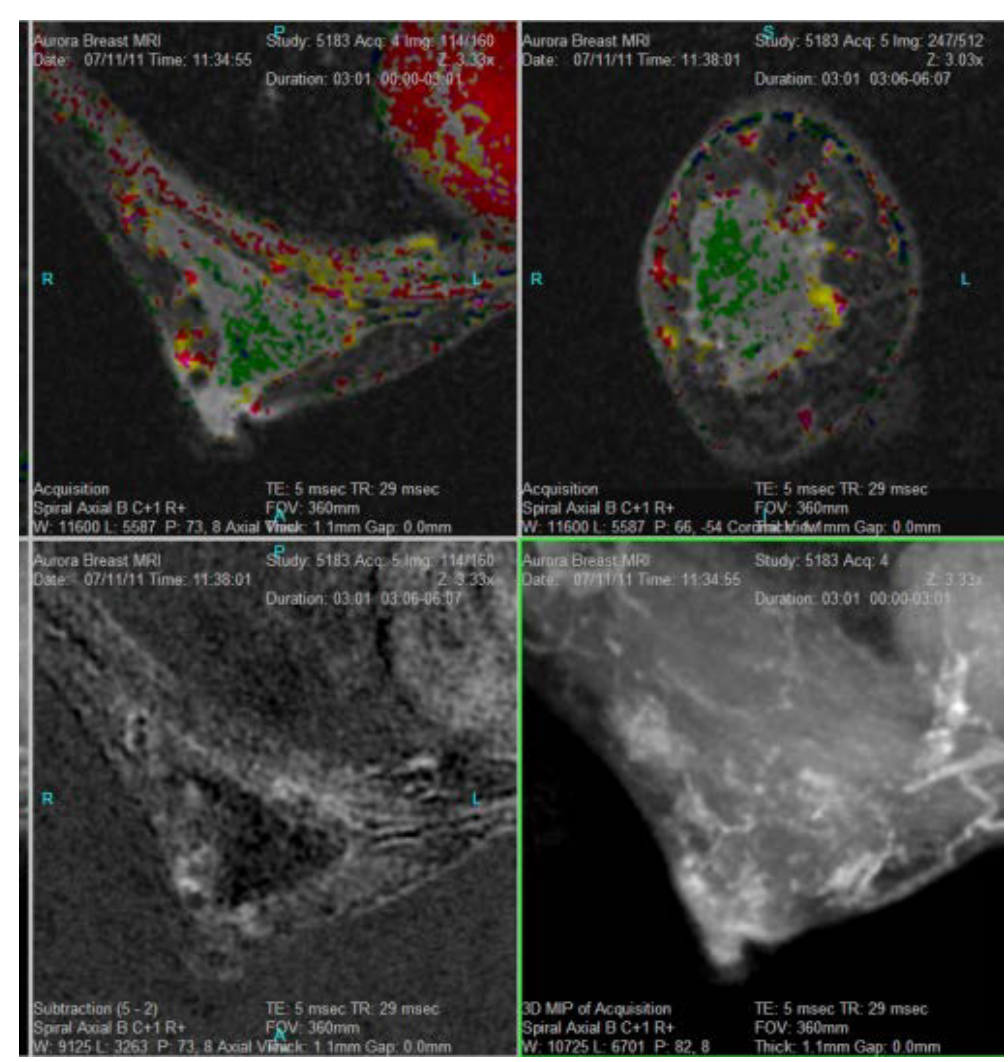

Figure 7: Small solid granuloma-like masses at right breast. 
Citation: Shen LK, Lin SL, Choy CS, Chan WP, Gasbarri M, et al. (2014) Using Breast MRI to Evaluate Complications of Autologous Fat Grafting. Surgery Curr Res 4: 197. doi:10.4172/2161-1076.1000197

Page 7 of 12

chronic inflammation of fat tissues, acted as the leading complication type in autologous graft breasts.

Granulomatous formation is caused by the failed attempts of the human immune system to eliminate foreign substances. Granulomas are seen in various diseases that relate to both infectious and noninfectious [25-27]. Granulomatous formation is a type of inflammation, with an important feature that it may contain necrosis. The identification of necrosis in granulomas is important because granulomas with necrosis tend to have infectious causes. However, in most of our cases with granulomatous formations that were associated with fat necrosis, infection did not occur. Fat necrosis has been reported in many different surgical procedures, such as reduction mammoplasty, mastectomy and post reconstructive procedures and others [28-35]. It was also shown that some over-obese animals are predisposed to fat necrosis without trauma and surgical inductions [36,37].

The mechanism of post-operative fat necrosis is still poorly understood but a variety of factors are thought to be some of the causes, such as direct trauma, infection, avascularity, hypoperfusion

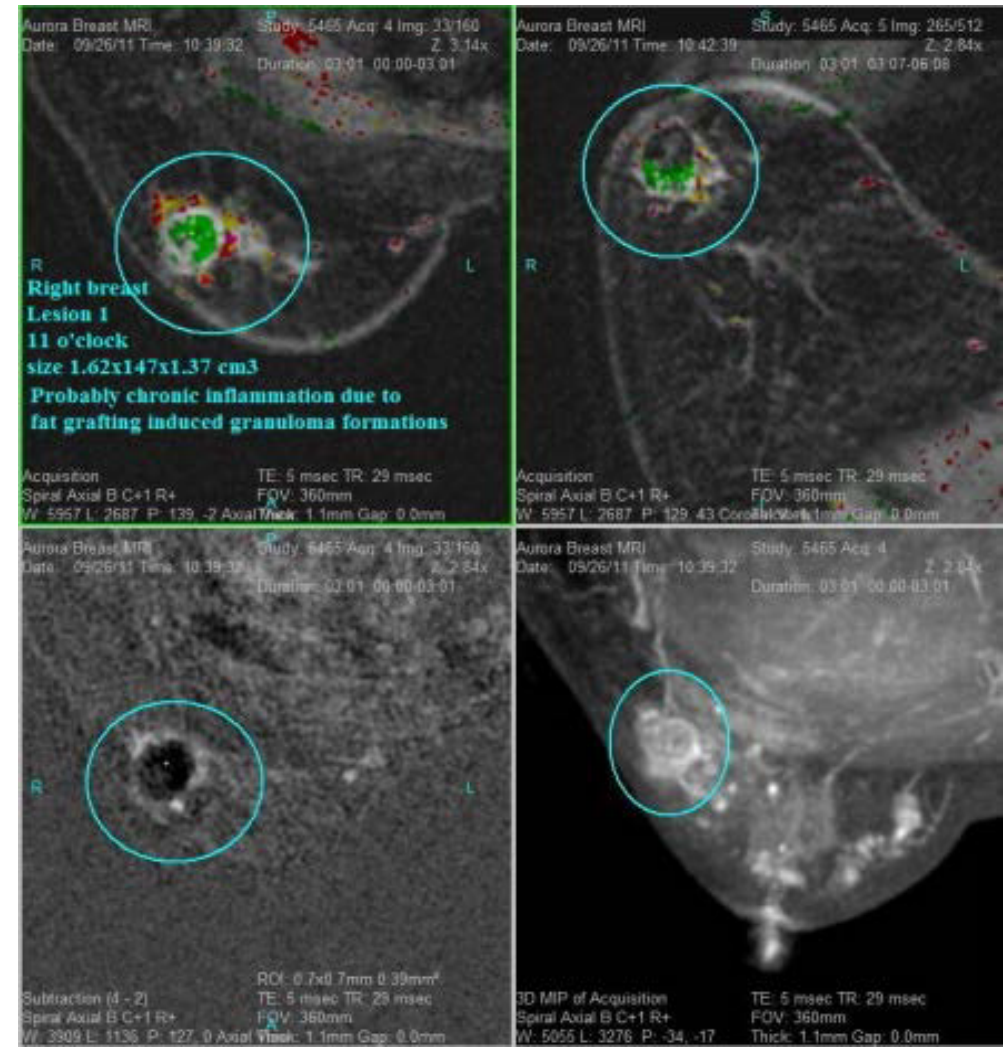

Figure 8: III-defined heterogenous enhanced masses at the superior lateral of the right breast ,with wall enhancement.

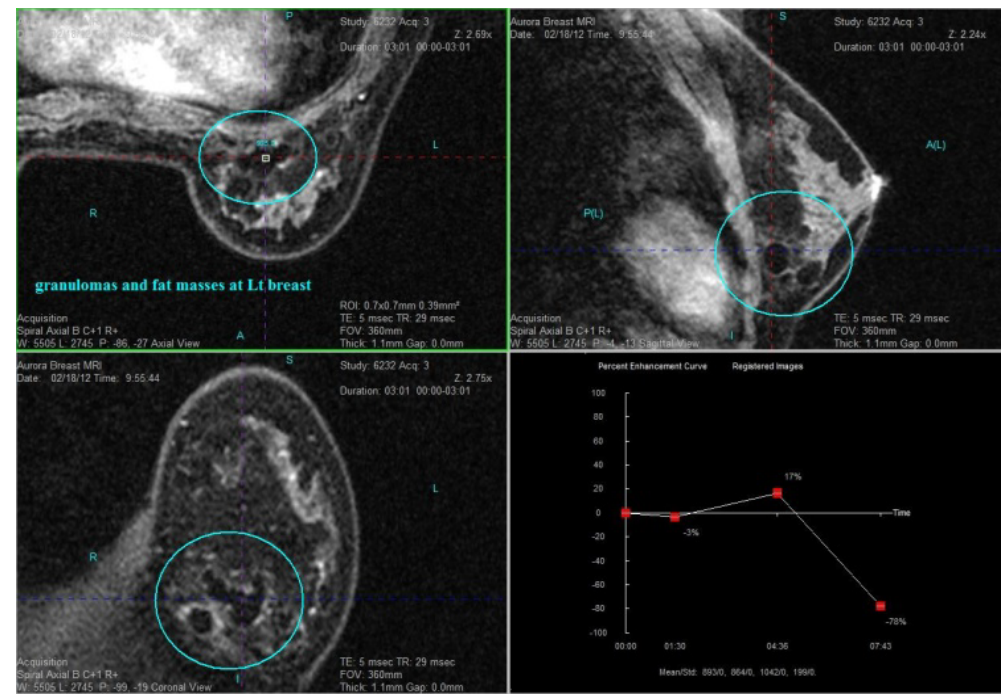

Figure 9: Multiple granulomas and fat masses at deep inferior of bilateral breasts. 
Citation: Shen LK, Lin SL, Choy CS, Chan WP, Gasbarri M, et al. (2014) Using Breast MRI to Evaluate Complications of Autologous Fat Grafting. Surgery Curr Res 4: 197. doi:10.4172/2161-1076.1000197

Page 8 of 12

and lipolytic enzymatic digestion [36-39]. To compare the image features of granulomas under mammography, sonography and breast MRI, it was found the typical mammographic pictures of granulomas as asymmetrical focal densities with no distinct margins, ill-defined masses with spiculated contours, and bilateral multiple ill-defined nodules were seen [40]. Under sonography, granulomas may appear as nonspecific discrete or heterogenous hypoechoic masses [38-40]. Thus, the mammography and sonography may not provide a conclusive result for determination of the necessity of surgical treatment, or to rule out malignancy [38]. It was believed that a major part of autologous fat injection for breast augmentation would not survive due to the associated physiological response of fat to succumb to necrosis and

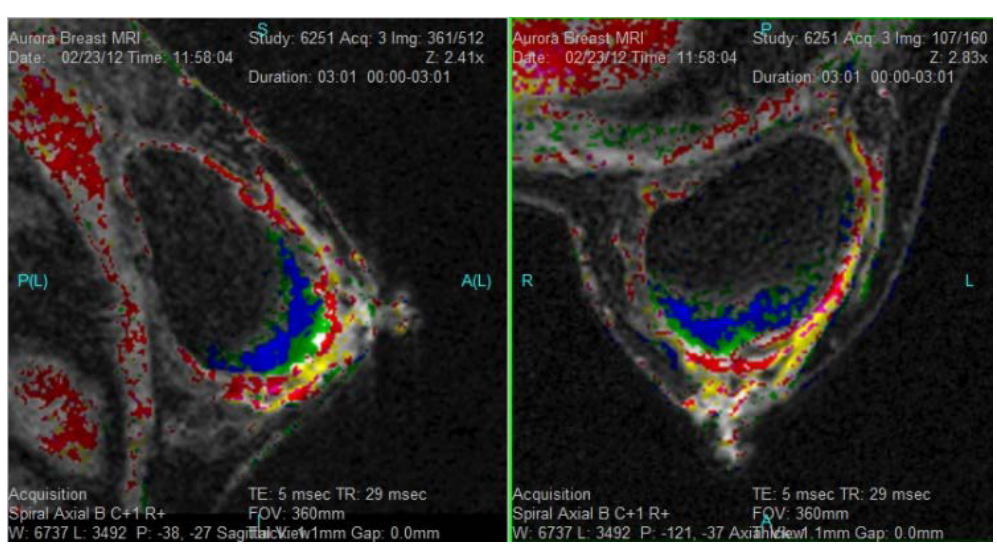

Figure 10: Fat grafted cavities at bilateral sides of subglandular regions. Some pockets with fluid at inferior of left breast. There are also enhanced glandular tissues at left anterior and bilateral lateral of breasts, represent mastitis.
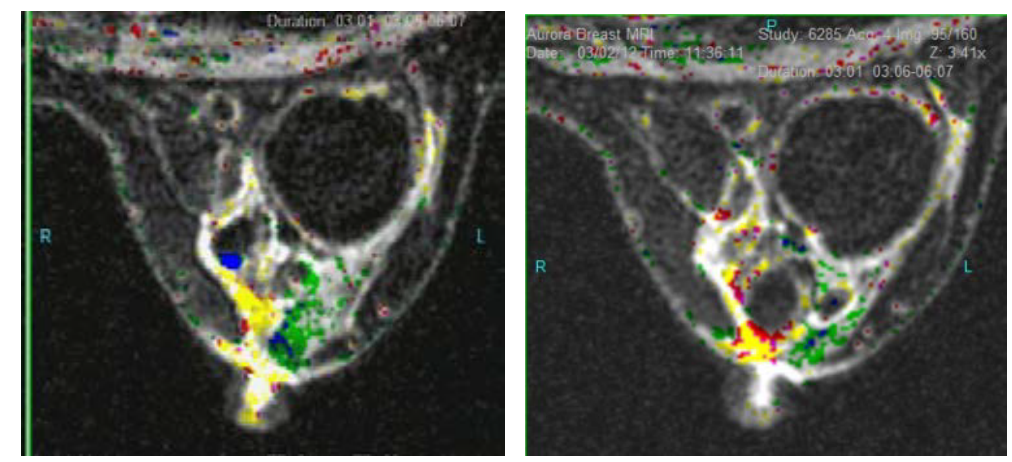

Figure 11: Multiple thick wall enhanced pockets with minimal fluid at inferior of left breast. There are also enhanced glandular tissues at left anterior and bilateral lateral of breasts, represent mastitis.
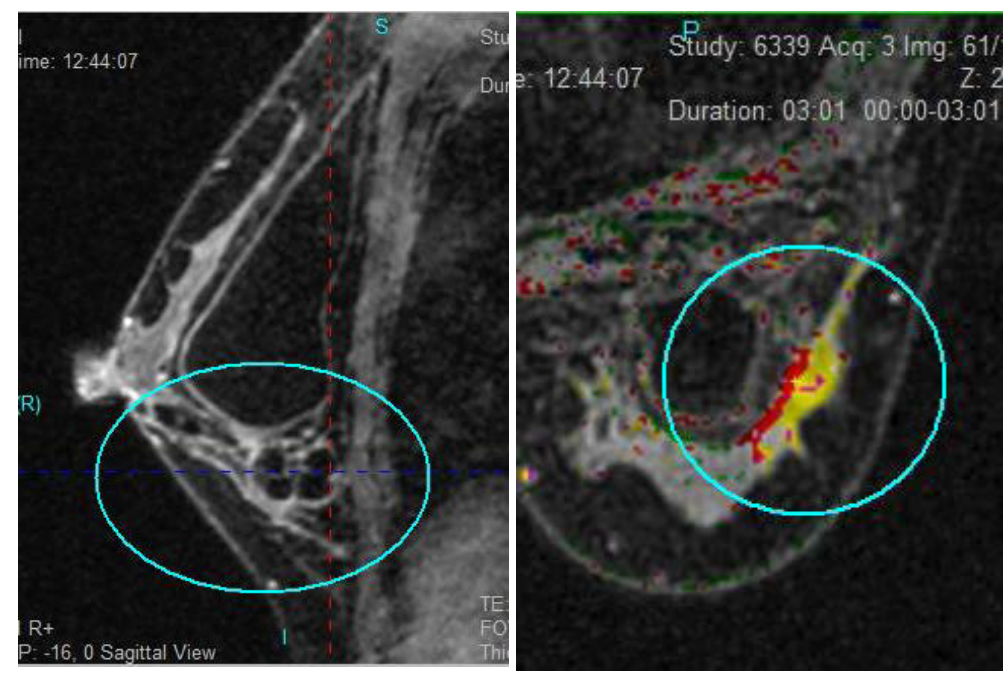

Figure 12: Post fat grafted and fat necrosis, with cavities within inferior of right breast (left figure); and enhanced area at left breast (right figure). 
Citation: Shen LK, Lin SL, Choy CS, Chan WP, Gasbarri M, et al. (2014) Using Breast MRI to Evaluate Complications of Autologous Fat Grafting. Surgery Curr Res 4: 197. doi:10.4172/2161-1076.1000197

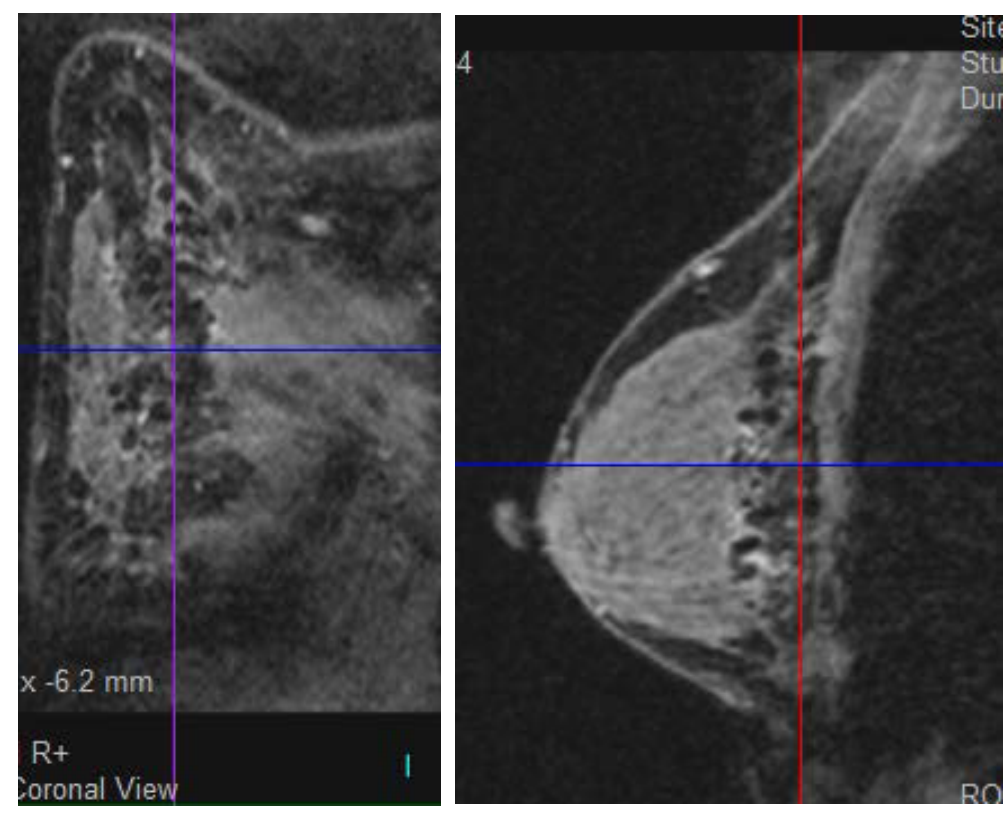

Figure 13: Honeycomb appearance at subglandular of right breast.

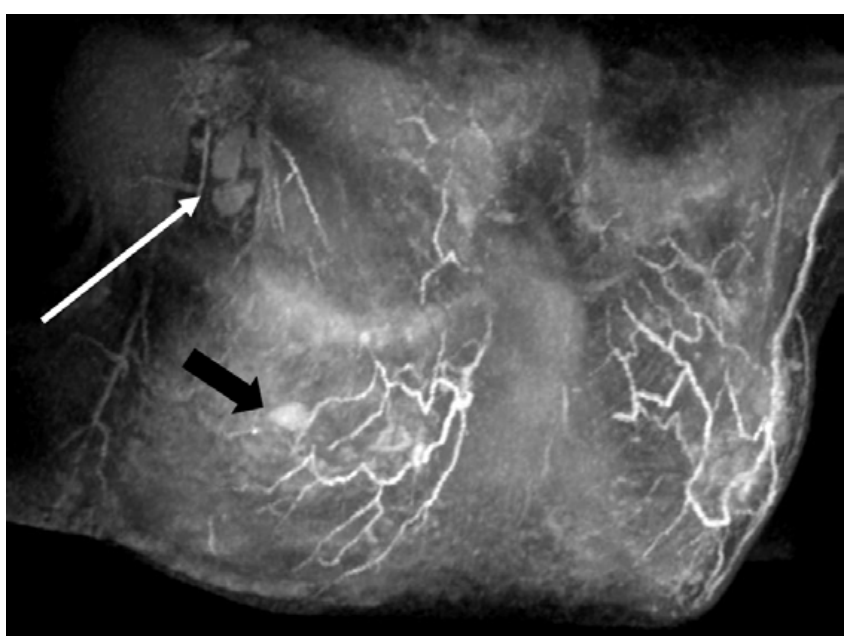

Figure 14: Post GD enhanced mastitis area (black thick arrow) at right breast with and reactive lymphadenopathy (thin white arrow).

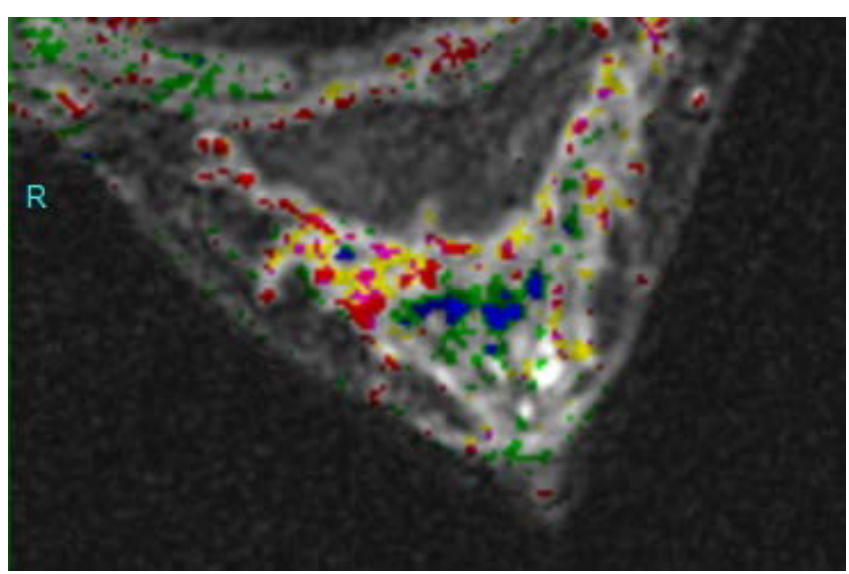

Figure 15: Subglandular autologous fat graft, with enhanced area at medial of left breast (red color). 


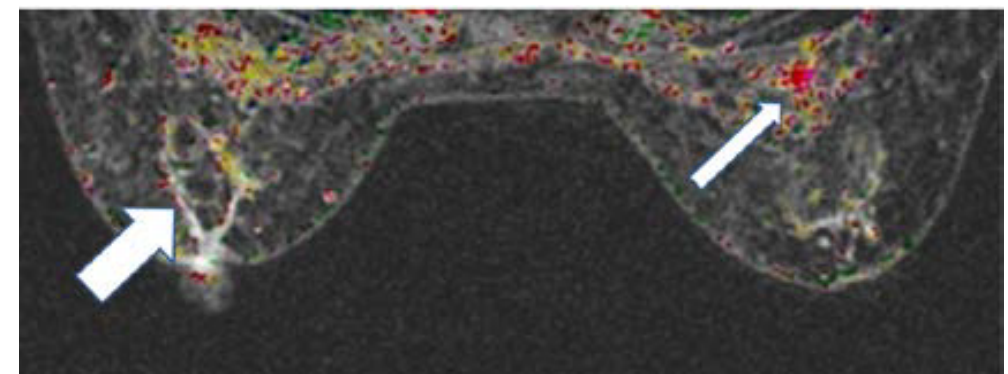

Figure 16: Post grafted fat necrosis at right breast (thick arrow); and enhanced area at left breast (thin arrow).
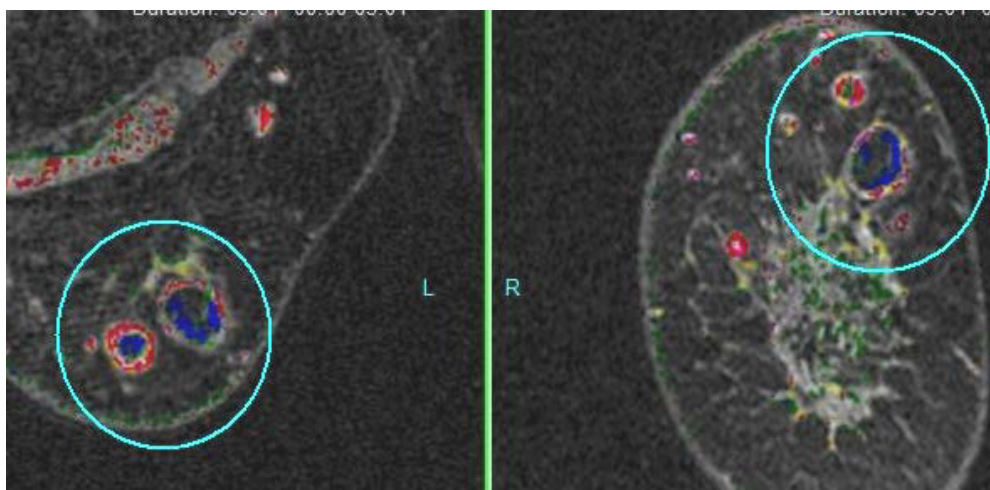

Figure 17: Fat necrosis, with cavities within left breast, with fluid like signal intensity.
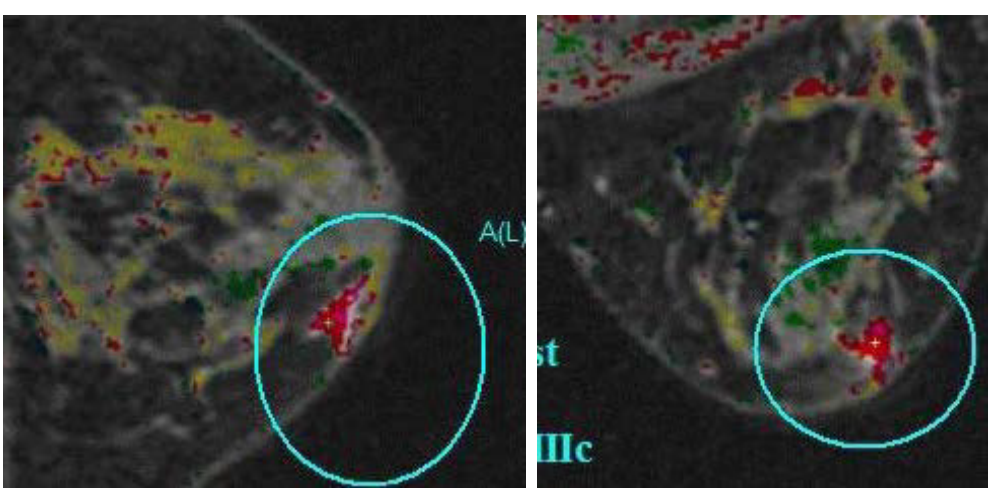

Figure 18: Focal patch form of non-mass lesion at left breast(circle) with obvious enhancement.
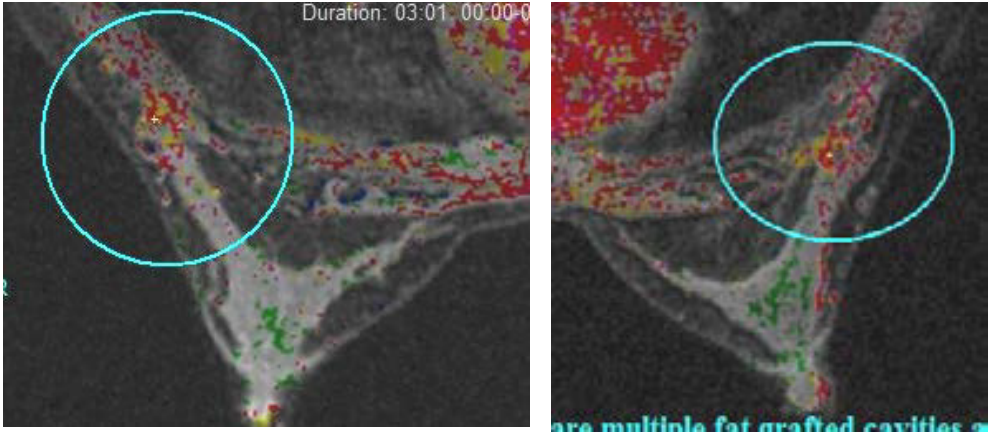

Figure 19: Post grafted fat necrosis at superior lateral of bilateral breasts (circles). 


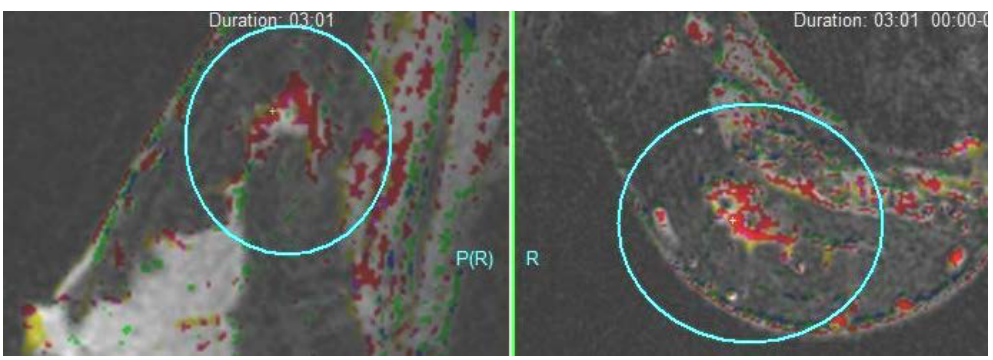

Figure 20: Area of mastitis with impending abscess formations at superior lateral of right breast.

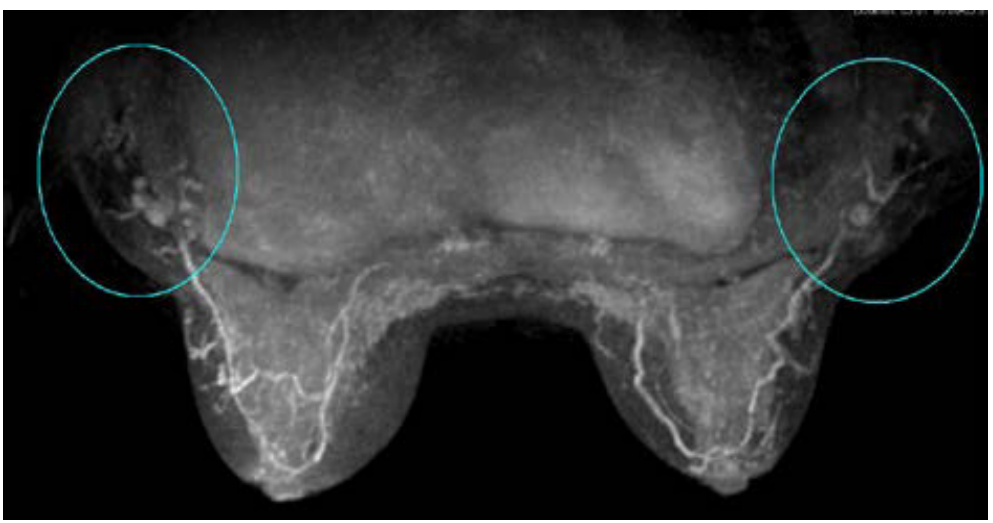

Figure 21: Nonspecific enhanced LNs in bil axillary regions.

then lead to scarring and calcification. Under mammography, the clusters of microcalcifications in the breast may be observed but cannot be distinguished from malignant calcifications. A common biopsy or a biopsy using mammographically guided needle localization is needed $[39,40]$.

On our dynamic breast MRI, the survival of fat grafted tissues can be qualitatively observed and quantitatively measured. Also, the most frequent finding of complication was focal or diffusely asymmetrical signal intensity changes with fluid or semi-fluid content, without significant mass effect. Nodular lesions, mass-like enhancement, ringlike enhancement, and nodular enhancement were observed. Although, most of the dynamic curves of post-gadolinium enhancement did not have characteristic findings, but based on the morphology and subtracted image, malignancy could be ruled out. From our result, we found four cases that had received operation, drainage or aspiration, but only five cases had higher levels of one or more than one of the following items: CRP, IgE or complement (C4) /ANA. We found the laboratory data are not able to predict all the corresponding post fat grafting infection and rejection with granuloma formations. It supports our contention that breast MRI should acting as first line screening method for early diagnosis and for treatment.

\section{Conclusion}

This is a study of using breast MRI to evaluate the conditions of post autologous fat grafting complications. Chronic inflammation with granuloma formations and fat necrosis has the highest incidence rate; we also found acute infection with abscess is the most urgent condition. Overall, $19 \%$ of the cases suffering complications had need of an additional operative treatment. Serum test for laboratory data should not be independently used as monitoring parameter for early detection of fat necrosis, granulomatous mastitis or abscess. However, breast MRI is a reliable imaging tool for precise diagnosis on the fat survival, fat necrosis, and other complications.

\section{Acknowledgment}

This study is funded by Taipei Medical University \& Shuang Ho Hospital (Project Number: 101TMU-SHH-22).The authors are grateful to Dr. Pai-Jung Huang and Ms. Jinnia Tsai (AUROA, ASIA) for their dedicated assistance.

\section{References}

1. Hinderer UT, del Rio JL (1992) Erich Lexer's mammaplasty. Aesthetic Plast Surg 16: 101-107.

2. Bircoll M (1987) Cosmetic breast augmentation utilizing autologous fat and liposuction techniques. Plast Reconstr Surg 79: 267-271.

3. Bircoll M (1990) Injectable technique of autologous fat transplantation. Plast Reconstr Surg 85: 149.

4. Castelló JR, Barros J, Vázquez R (1999) Giant Liponecrotic Pseudocyst after Breast Augmentation by Fat Injection. Plast Reconstr Surg 103: 291-293.

5. Valdatta L, Thione A, Buoro M, Tuinder S (2001) Case of Life-Threatening Sepsis After Breast Augmentation by Fat Injection. Aesthetic Plast Surg 25: 347-349.

6. Yoshimura K, Asano Y, Aoi N, Kurita M, Oshima Y (2010) Progenitor-Enriched Adipose Tissue Transplantation as Rescue for Breast Implant Complications. Breast J 16: 169-175.

7. Hyakusoku H, Ogawa R, Ono S, Ishii N, Hirakawa K (2009) Complications after Autologous Fat Injection to the Breast. Plast Reconstr Surg 123: 360-370.

8. Yoshimura K, Sato K, Aoi N, Kurita M, Hirohi T, et al. (2008) Cell-assisted lipotransfer for cosmetic breast augmentation: supportive use of adiposederived stem/stromal cells. Aesthetic Plast Surg 32: 48-55.

9. Brown FE, Sargent SK, Cohen SR, Morain WD (1987) Mammographic changes following reduction mammaplasty. Plast Reconstr Surg 80: 691-698.

10. Maillard GF (1994) Liponecrotic cysts after augmentation mammaplasty with fat injections. Aesthetic Plast Surg 18: 405-406.

11. Mitnick JS, Roses DF, Harris MN, Colen SR (1990) Calcifications of the breast after reduction mammoplasty. Surg Gynecol Obstet 171: 409-412. 
Citation: Shen LK, Lin SL, Choy CS, Chan WP, Gasbarri M, et al. (2014) Using Breast MRI to Evaluate Complications of Autologous Fat Grafting. Surgery Curr Res 4: 197. doi:10.4172/2161-1076.1000197

Page 12 of 12

12. Teh W, Wilson AR (1998) The role of ultrasound in breast cancer screening. A consensus statement by the European Group for breast cancer screening. Eur J Cancer 34: 449-450.

13. Delay E, Garson S, Tousson G, Sinna R (2009) Fat Injection to the Breast: Technique, Results, and Indications Based on 880 Procedures Over 10 Years. Aesthet Surg J 29: 360-376.

14. Leung TK, Chu JS, Huang PJ, Lin YH, Lee CM, et al. (2010) Breast MRI for monitoring images of an "adenomyoepithelioma with malignant features", before, during, and after chemotherapy. Breast J 16: 652-653.

15. Leung TK, Huang PJ, Lee $\mathrm{CH}$, Chen CS, Wu CH, et al. (2010) Is Breast MRI Screening More Effective Than Digital Mammography in Asian Women? Journal of Experimental \& Clinical Medicine 2: 245-250.

16. Leung TK, Huang PJ, Sun LM, Chu JS, Chen CS, et al. (2012) Silicone breast implant with intracapsular rupture coexisting with locally advanced carcinoma. Breast J 18: 76-77.

17. Leung TK, Huang PJ, Lee CM, Chen CS, Wu CH, et al. (2010) Can breast magnetic resonance imaging demonstrate characteristic findings of preoperative ductal carcinoma in situ in Taiwanese women? Asian J Surg 33:143-149.

18. Jian H, Yan-Yan W, Qiang W, Zhi-Qian H, Jian-Quan Z (2008) Endoscopic debridement and drainage of the breast giant liponecrotic pseudocyst after augmentation mammaplasty by fat injective autotransplantation. Journal of Chinese Clinical Medicine 11.

19. Niechajev I, Sevćuk O (1994) Long-term results of fat transplantation: clinical and histologic studies. Plast Reconstr Surg 94: 496-506.

20. Castelló JR, Barros J, Vázquez R (1999) Giant liponecrotic pseudocyst after breast augmentation by fat injection. Plast Reconstr Surg 103: 291-293.

21. Kaufman MR, Miller TA, Huang C, Roostaeian J, Wasson KL, et al. (2007) Autologous fat transfer for facial recontouring: is there science behind the art? Plast Reconstr Surg 119: 2287-2296.

22. Smith P, Adams WP Jr, Lipschitz AH, Chau B, Sorokin E, et al. (2006)Autologous Human Fat Grafting: Effect of Harvesting and Preparation Techniques on Adipocyte Graft Survival. Plast Reconstr Surg 117: 1836-1844.

23. Minn KW, Min KH, Chang H, Kim S, Heo EJ (2010) Effects of fat preparation methods on the viabilities of autologous fat grafts. Aesthetic Plast Surg 34: 626-631.

24. Mu DL, Luan J, Mu LH, Xin MQ (2009) Breast Augmentation by Autologous Fat Injection Grafting: Management and Clinical Analysis of Complications. Ann Plast Surg 63: 124-127.
25. Woodard BH, Rosenberg SI, Farnham R, Adams DO (1982) Incidence and nature of primary granulomatous inflammation in surgically removed material. Am J Surg Pathol 6: 119-129.

26. Hunter DC, Logie JR (1988) Suture granuloma. Br J Surg 75: 1149-1150.

27. Adams DO (1976) The granulomatous inflammatory response. A review. Am J Pathol 84: 164-192.

28. Dabbah A, Lehman JA Jr, Parker MG, Tantri D, Wagner DS (1995) Reduction mammaplasty: an outcome analysis. Ann Plast Surg 35: 337-341.

29. Leibman AJ, Styblo TM, Bostwick J 3rd (1997) Mammography of the postreconstruction breast. Plast Reconstr Surg 99: 698-704.

30. Jouini S, Sehili S, Ksontini R, Khelifi A, Chtourou S, et al. (1996) [Pseudotumora abdominal cysto-steato-necrosis: an unusual etiology]. Ann Radiol (Paris) 39: 111-114.

31. Silverman AK, Michels EH, Rasmussen JE (1986) Subcutaneous fat necrosis in an infant, occurring after hypothermic cardiac surgery. Case report and analysis of etiologic factors. J Am Acad Dermatol 15: 331-336.

32. Lee PC, Howard JM (1979) Fat necrosis. Surg Gynecol Obstet 148: 785-789.

33. Voinchet V, Boissinot P, Magalon G (1995) [Post-traumatic liponecrosis Apropos of a clinical case]. J Chir (Paris) 132: 305-308.

34. Marshak RH, Lindner AE, Maklansky D, Goldberg MD (1980) Mesenteric fat necrosis simulating a carcinoma of the cecum. Am J Gastroenterol 74: 459-463.

35. Janigan DT, Morris J, Hirsch D (1992) Acute skin and fat necrosis during sepsis in a patient with chronic renal failure and subcutaneous arterial calcification. Am J Kidney Dis 20: 643-646.

36. Gregory NG, Christopherson RJ, Lister D (1986) Adipose tissue capillary blood flow in relation to fatness in sheep. Res Vet Sci 40: 352-356.

37. Katamoto H, Yukawa T, Shimada Y (1996) Lipogenic and lipolytic activities in isolated adipocytes from cattle with fat necrosis. Res Vet Sci 61: 214-217.

38. Digirolamo M, Esposito J (1975) Adipose tissue blood flow and cellularity in the growing rabbit. Am J Physiol 229: 107-112.

39. Wang CF, Zhou Z, Yan YJ, Zhao DM, Chen F, et al. (2011) Clinical analyses of clustered microcalcifications after autologous fat injection for breast augmentation. Plast Reconstr Surg 127: 1669-1673.

40. Ozturk M, Mavili E, Kahriman G, Akcan AC, Ozturk F (2007) Granulomatous mastitis: radiological findings. Acta Radiol 48: 150-155. 